\title{
Elemental aesthetics: On artistic experiments with solar energy
}

Sasha Engelmann and Derek McCormack

Dr. Sasha Engelmann

Lecturer in GeoHumanities

Royal Holloway University of London

sasha.engelmann@rhul.ac.uk

Prof. Derek McCormack

School of Geography

University of Oxford

derek.mccormack@ouce.ox.ac.uk 


\begin{abstract}
In recent years geographers and others have begun to tease out the ontological, epistemological, and ethico-political implications of thinking about and with the elemental. In this article we contribute to this work by considering the relation between the elemental and the aesthetic. More precisely, we argue for the importance to geographical thinking of the development of an elemental aesthetics attuned to the diverse ways in which the elemental is sensed in bodies and devices of different kinds as part of the distribution of ethical and political capacities. Our argument is developed via participatory engagement with the work of contemporary artist and architect Tomás Saraceno, central to which is the ongoing attempt to craft aesthetic works that mobilize the elemental energy of the sun in order to generate novel modes of sensing, traveling, and living in the air. Drawing on participatory research and engagement with Saraceno’s Aerocene project, we show how his work helps us reimagine distributions of the capacity to sense the elemental. In the process, we reflect upon some of the ways in which these experiments can inform the shape and orientation of geographical engagements with an elemental aesthetics.
\end{abstract}

Keywords: atmosphere, art, elemental, Saraceno, solar energy, sun 


\section{Introduction}

The elemental has re-emerged recently as an important focus of philosophical, political, and ethical concern within and beyond geography (see, for instance, Fannin and Jackson 201 1; Martin 2011; Adey 2015; Engelmann 2015a; McCormack 2015 2017; Squire 2016; Cohen and Duckert 2016; Padilla, 2009; Mentz 2010). In this diverse work the broad category of the elemental figures variously as a necessary condition for different forms of life (Ingold 2010a); as the phenomenological horizon of sensory and affective experience (Martin 2011); and as the materialist limit of much work on air and atmosphere (Adey 2015). Resisting neat definition, the elemental can be and is invoked in recent work to mean different, but related things. Most importantly, it can refer to different categories of matter, particularly air, earth, water, fire; to the environmental milieu within which multiple forms of life are immersed; and, more narrowly, to a range of scientifically defined substances. In many ways, then, the elemental is alluring because it both captures something tangible about the world while also remaining excessive of human agency or intervention.

For geographers and others, engaging with different versions and senses of the elemental poses important questions. Some of these are ontological, and involve thinking about the materiality of the elemental in ways that avoid simple oppositions between matter and representation (Anderson and Wylie 2009). Other questions are epistemological, and concern the problem of how variations in the elemental are sensed within and across bodies by virtue of their capacities to affect and be affected (Martin 2011; Jackson and Fannin 2011; Craig 2011). And others are political, and involve thinking about different ways in which the elemental becomes implicated in 
assemblages and technologies of power, becoming the reference point, for instance, of various modes of territoriality and verticality (Adey 2015; Squire 2015).

In this paper we further develop these emerging geographies of the elemental by exploring how an engagement with the question can inform geographical understandings of aesthetics. While a concern with aesthetics has long been an aspect of thinking geographically, the scope of such engagements has recently expanded, and particularly so in relation to matters of ecological and environmental concern (see, for example, Dixon 2009; Sharpe 2012; Hawkins and Straughan 2015; Hawkins, Marston, Ingram, and Straughan 2015; Yusoff 2015; Ingram, 2016; Kingsbury 2016). Cutting across such work is the claim the aesthetic is not some kind of superficial veneer layered over more important or substantive issues: rather, as a domain of sense-making, the aesthetic is critical to how the material dynamics of the world are sensed and take shape as matters of concern. Equally importantly, more than just a limited domain of judgment or taste, in much recent work within and beyond geography, the aesthetic is taken to constitute a heterogeneous field of sensing distributed across the capacities of different bodies, both human and non-human (Rànciere 2004; Dixon 2009; Dixon, Hawkins, and Straughan 2012; Clark 2013; Lorimer 2012; Yusoff 2015).

By bringing together questions of the elemental and aesthetic, in this paper we explore the promise of an elemental aesthetics organized around the question of how to become attuned to different manifestations of what Peter Adey (2015) has recently called the "force of the elemental". This is a force which, while subject to various technical and scientific practices, nevertheless remains excessive of representational practices and technologies. So, while we can specify the atomic and chemical properties of particular elements, the elemental denotes a force which exceeds these 
specifications through its capacities to generate different conditions in which sensing takes place. Our emphasis then in what follows is on an elemental aesthetics which goes beyond a concern with how the elemental is depicted in various forms of representational or figurative art, even though we acknowledge the ongoing importance and value of such art. The kind of elemental aesthetics with which we are concerned here is organized around the challenge of making sensible through various experiments how the elemental shapes and sustains diverse worlds. This is an elemental aesthetics concerned with enhancing our capacities to be affected by, and to sense, feel, and imagine elemental variations in the worlds we inhabit. Enhancing such capacities, we argue, is crucial to any attempt to make the conditions of the present palpable as a prelude for the articulation of different forms of ethical-political awareness.

Artistic experiments have the potential to play an important role in this process. In this paper we consider ongoing artistic experiments that mobilize the force of the elemental in order to craft distinctive kinds of atmospheric objects, spaces, and imaginaries. More specifically, we focus on the work of contemporary artist and architect Tomás Saraceno, particularly his ongoing experiments with the elemental force of the sun in order to craft novel investments in atmosphere. These experiments, in which we have participated in different ways, are important because they mix the technical, the aesthetic, and the ethico-political in ways that encourage us to speculate upon the scope of the elemental as a matter of concern. Critically, in doing so, these experiments provide practical and conceptual resources for thinking through the material politics of the Anthropocene, and for developing conceptual-empirical speculations that operate interstitially to such epochal terms. 
The paper is organized as follows. We begin by outlining how geographers and others have engaged with questions of the elemental and aesthetics. We then consider artistic experiments with the elemental, focusing in particular on the significance of the sun, and on solar energy, in these experiments. Following this, we discuss a number of collaborative projects in which Tomás Saraceno is involved, foregrounding their capacities to generate opportunities for exploring how an elemental aesthetics can emerge as a distributed arrangement of bodies, spaces and forms of life. In the conclusion of the paper we reflect upon the wider implications for geographers of engaging and experimenting with an elemental aesthetics.

\section{The elemental and the aesthetic}

To begin we wish to consider in more depth how the question of the elemental has returned as a matter of concern for geographers and others. Unsurprisingly, the category of the elemental is differentiated and can be grasped in a range of versions. A number of these versions are particularly important, however, in shaping and giving impetus to recent engagements with the elemental across the social sciences and humanities. First, the re-emergence of the elemental can be understood as part of a wider and ongoing effort to understand the material ontology of earth, world, and life (Anderson and Wylie 2009; Cohen and Duckert 2015). While it is tempting to imagine this is merely symptomatic of a wider critical response to the looming category of the Anthropocene, we should not forget that the question of the elemental is a long standing concern in various philosophical traditions. In classical Greek thought, for instance, the attempt to think about the world in terms of a limited number of elemental matters was associated with the writing, fragmentary as it is, of 
Empedocles. For Empedocles, and in turn for Plato, the world was composed of air, earth, fire, and water, and the relations between these elements were shaped by affective energies including love and strife (MacCauley 2010). As ontological claims, such ideas are not credible of course. But they are potentially valuable as imaginative resources for more recent efforts to think about the crafting of an elemental poetics attentive to the energy of diverse agencies (Cohen 2011; 2014; Cohen and Lowell Duckert 2015; Padilla 2009; Mentz 2010). It is precisely the imaginative poetics of the elemental which makes it so alluring for these authors. They are drawn to the elements, in part, for their dramatic materiality, for how their "narratives are noisily audible, their activity energetic and obvious” (Cohen 2014: 55). Indeed, as Jane Bennett (2010) has argued in relation to the work of Lucretius, it is perfectly possible to mobilize archaic material imaginaries in order to animate and enrich ongoing efforts to speculate upon ontological ethics and politics. In that sense, the category of the elemental provides an imaginative resource for different versions of speculative realism and of new materialism, in which the emphasis shifts and slides between the fundamental importance of entity, relation, and process.

Second, the elemental has become an alluring category for thinking through the processual materiality of the environmental milieus in which different forms of life are generatively immersed (Durham Peters 2015: Ingold 2015). Here the Empedoclean fourfold division actually provides some orientation insofar as it reminds us of how forms of life live, move, and associate by virtue of their immersion in water, earth, or air. This might seem like an obvious claim to make. And yet, with some notable exceptions, geographers and others are arguably only beginning to elaborate the kind of more-than-human phenomenology that is sufficiently attentive to the modes of living and moving that take place through the affordances of different 
elemental milieu (see Ingold 2015). That said, perhaps the most obvious way in which this broader project is being pursued is through increased attention to air and atmosphere as elemental milieus for different forms of life. While much of this work has focused on the technological and political assemblages of different forms of aerial and atmospheric life (Adey 2010; 2014), recent work has also begun to pay attention to the agency of air and atmosphere in shaping forms of human and non-human life in ways that are excessive of control and calculability (see Jackson and Fannin 2011; Engelmann 2015b). However, there remains a great deal of scope for exploring how the agency of atmospheric milieus participate in the crafting of new forms of association and life, not least because in sensing variations in these milieus we are also sensing the force of something whose origin lies beyond our sphere of planetary concern.

Third, the re-emergence of the elemental is part of a wider effort to think about the role that distinctive materials with very specific properties play in shaping geographies (see, for instance, Hecht 2012). Here the category of the elemental provides an important constraint insofar as it refers to the organization of matter and energy into specific materials with relatively predictable capacities to affect and be affected. This is the elemental as the physico-chemical: the elemental as a configuration of matter whose properties and capacities defines and shapes organic and inorganic entities. This is the elemental grasped in terms of bonds, affinities, and reactions, capacities whose distribution is diagrammed across the rows and columns of the periodic table of elements. This is not to reduce materiality to the terms of the scientific gaze, or to suggest that each of the elements on this table always exists as a discrete entity. Nor, however, is it to deny the importance of this diagram in shaping a range of associations, some of which are malign and some benign. Indeed, tracing 
these associations, and the sometimes fragile worlds that gather round them, is an important part of any effort to think through the elemental (Hecht 2012; Shapiro 2015). As such, we can think of experiments with the elements as efforts to sense the bonds that ally human practitioners with the restless materials making up the world (Cohen 2014).

A fourth reason that thinking with the elemental is important is because it provides a way of speculating about the kinds of ethics and politics of life that emerge in relation to the Anthropocene as a diagnostic figure of thought (see also Lorimer 2015). On one level, this means thinking both about how diverse assemblages of life are sustained or undermined by the properties of different elemental matters and milieus. On another, it is about examining how human activity may be remaking these matters and milieus. In response, an ethics of the elemental might begin, then, in speculating about how the elemental is implicated in the conditions that sustain valued forms of life and our responsiveness to these conditions. And a politics might begin with efforts to think about how the capacity to modify exposure to these conditions is differentially distributed across bodies, devices, and territories of different kinds (Adey 2015; Squire 2016). At the same time, foregrounding the force of the elemental also reminds us of the circumstance-specific natures implicated in claims about the Anthropocene as a new geological cycle. And in doing so, it might also have the capacity to prompt us to develop other speculative imaginaries for thinking about the conditions of the present.

As we have already signaled, our claim here is that foregrounding aesthetics has the capacity to make an important contribution to these engagements with the elemental. The relation between geography and aesthetics has become the focus of a range of different conceptual and empirical interventions, informed by different 
theoretical approaches and perspectives (see, for example, Dixon 2009; Sharpe 2012; Hawkins and Straughan 2015; Hawkins, Marston, Ingram, and Straughan 2015; Yusoff 2015; Ingram 2016; Kingsbury 2016). As much of this work demonstrates, geographers have taken the question of aesthetics well beyond a concern with the analysis and experience of representations and representational practices, even while remaining attentive to the importance of these practices. Instead, aesthetics becomes a way of denoting a wider sensorium, variously backgrounded and foregrounded, within which diverse forms of experience take shape (see also Thrift 2008). In these terms, the aesthetic does not so much refer to a privileged domain of practice, but constitutes a heterogeneous, distributed field of sensing and feeling (Rànciere 2004) which provides the conditions in which different forms and entities emerge as potentially palpable matters of ethical and political concern.

Equally importantly, the aesthetic is also increasingly recognized as a field that extends beyond human experience. It is a field shaped and conditioned by a range of non-human agents and forces, and the capacity to sense variations in this field is distributed across and beyond bodies, objects, and diverse forms of organic life (Dixon 2009; Dixon, Hawkins, and Straughan 2012; Clark 2013; Lorimer 2012; Yusoff 2015). Because of this, when we are thinking about the relation between the aesthetics and the elemental, two questions become particularly important. The first is the question of how the elemental shapes the conditions of aesthetic experience: that is, how do different versions of the elemental contribute to the generation of the conditions of possibility for sensing as such? The second question concerns the kinds of experiments, and experimental devices, that might contribute to enhancing capacities to sense the elemental in a range of circumstances. 


\section{The force of the solar}

In the remainder of the paper we wish to give these questions focus by thinking about artistic experiments with the elementality of the sun. Doing this helps us hold together the different senses of the elemental outlined earlier. Most obviously perhaps, the sun foregrounds with stark clarity the power of the elemental in a physico-chemical sense, composed as it largely is of hydrogen and helium in different states of combustion (See Fisher 2010). Equally, the sun foregrounds the ontological sense of the elemental, tensed as it is between the status of entity and process. On the face of it, the sun appears and acts as an entity, as something with a unified existence whose essence is withdrawn from its relations with all other entities (on this account of entities and withdrawal see, for instance, Harman 2010; Bogost 2012; Morton 2013). The earth aside, the sun is the elemental entity upon whose alluring emanation we depend most, but whose essence remains absolutely beyond us. And yet the sun might just as easily be understood as pure process: as a continuously explosive set of transformations, radiations, and emanations that define the distinctive form of its being as becoming. Taken literally, this means that the sun can be apprehended through the transmission of radiation - the product of physicochemical nuclear processes in the sun - to the earth, where it drives a range of atmospheric and terrestrial processes.

In this view, as the philosopher and theologian Don Cupitt writes, the sun "lives beyond the distinction between noun and verb, substance and activity, being and doing. In the old scholastic language, it is pure Act. It coincides with its own continuous outpouring” $(1995,14)$. This continuous outpouring is obviously critical to life on earth, as part of its economy of excess. As George Bataille writes, “[s]olar energy is the source of life's exuberant development. The origin and essence of our 
wealth are given in the radiation of the sun, which dispenses energy - wealth without any return. The sun gives without ever receiving” (Bataille 1991, 28). Equally, as Gaston Bachelard notes, the pure process of the sun is also a 'pure dynamism’: the “exogenesis” of its light (Pasquinelli 2015) is inseparable from the complex energetic dynamics of atmosphere. Moreover, following Tim Ingold we might say that the sun is "not... an object that moves across the sky. Rather it is identified as the path of its movement through the sky, on its daily journey from the eastern to the western horizon” $(2011,72)$. At the very least, then, from the perspective of the earth and its dwellers, the ontological status of the sun and of the solar always flickers between entity and process.

We don't need to resolve this tension in order to grasp a third way in which the sun helps us foreground the elemental. This is through its influence on the elemental conditions that sustain forms of life on the earth. Solar processes are particularly obvious drivers of the meteorological dynamics of the atmosphere. To be sure, they are not the only drivers: the dynamic geological and thermal make-up of the earth and the particular characteristics of its spin and rotation also play a part. Nevertheless, we can understand life, in some respects at least, as the compositional form of a material solar economy as effusive excess (Bataille 1991). Seen thus, as Michel Serres claims, "the ultimate capital is the sun” (Serres 1980). This solar economy is, of course, a political one, not least because its capital can be harnessed technically in ways that translate excess into exchange value. We can see this, for instance, in engineering projects that promise low-carbon solutions to the problem of energy supply and security, or through the emergence of geo-engineering as a speculative experimentalism through which to modify the Earth’s absorption and reflection of the sun’s radiation (see Macnaghten and Szerszynski 2013). These 
increasingly large-scale projects point to how the relations between the earth and the sun are being refigured and re-engineered through the speculative economies of the Anthropocene (Crutzen 2006; Clark 2013 2014). It is worth remembering however that the technical articulation of relations with solar energy is not restricted to, nor as recent as, the development of large-scale speculative projects. The technical sustainability of many forms of life is conditioned by the problem of modifying relations with solar energy through practices, materials, and devices that either intensify or dampen its force (Sloterdijk 2011; Serres 2008). Long before solar panels, the elemental force of the solar was already part of the technical and machinic organization of life on earth through the elaboration, for instance, of a range of forms of envelopment, from skin to shades to screens to walls.

The articulation of elemental relations with the sun through technical practices and materials is also ethico-political: it is about the distribution of capacities to act and the conditions under which these capacities are made possible or constrained. It is about how the elemental force of solar energy can be taken into account, while always remaining excessive of, assemblages of political agency. Thinking about these questions is particularly important in the context of the contemporary juncture, in which the problem of reworking our relations with different forms of energy and the economies they implicate has become especially urgent. There is, to be sure a certain kind of heliocentrism in this claim, one which thinkers like Lyotard and Bataille rehearse (for a critique, see Serres 1980), and one that does not countenance the possibility that one day life will be revealed to be far more distributed in the universe than we imagine. Nevertheless, given the circumstances, working within the constraint of this heliocentrism requires us to rethink the relation between the solar and the terrestrial. What might it mean to explore possibilities for speculating with the 
force of the solar that gather or generate other, less apocalyptic, more charming (Buck 2015) and more open-source versions of life in the shadow of the Anthropocene and Capitalocene? ${ }^{1}$ How might we think with the force of the solar outside of the shadow of these conceptual formations and the conditions they diagnose, without denying the trouble they implicate us in (Haraway 2016)? How might experiments with the elemental force of the sun reattune us to the elemental conditions of the present? And how might such experiments contributed to the redistribution of capacities to sense the force of the elemental?

To pose such questions at the contemporary conjuncture is to speculate about how it might be possible to develop more hopeful forms of association powered by the elemental force of the solar. It is to cast new light on how the sun shapes the circumstances of life as we sense, think, and feel them, allowing different modes of relationality to emerge. More prosaically, it is to recognize that the sun makes the air move, and to recognize that the wind we feel is always a solar-powered wind. It is to ask how such elemental processes might become co-conspirators in the generation of different forms and arrangements of life. Critically, the pre-condition for addressing these questions is primarily an aesthetic one, insofar as it involves the capacity to sense variations in the elemental. Part of this sensing is already available to us because human bodies are implicated in forms of life immersed in the turbulent variability of what Tim Ingold (2010a) calls "weather worlds": these are fields of elemental experience in which affects and percepts precipitate, distill, or condense. But the elemental can also be sensed through the movement of nonhuman devices, objects, and materials as they respond to variations in heat, light, temperature, and pressure. It is the possibility and promise of such sensing, thinking, and moving with the elemental force of the sun that animates our exploration in what follows of 
distinctive experiments with solar energy that mobilize novel arrangements of bodies, materials, and devices.

\section{Artistic experiments with the solar}

While the aesthetic capacities to sense the elemental are abroad in the world and are not specific to any particular set of practices or technologies, one of the values of artistic practices is that they generate circumstances in which these capacities can be foregrounded and distributed. Here, of course, we also need to note that the force of the elemental is intimately implicated in the emergence of forms of artistic expression. The very light provided by the sun provides both the condition and problematic for most representational art practices (Ingold 2015; Pasquinelli 2014 2015), and indeed for the question of what can be represented (see also Derrida 1981) and seen as such (Evans 1998). Equally, the question of how to represent the sun, and how to render apparent its symbolic significance, has been and remains a key theme in art across a range of cultural traditions and artistic genres, encapsulated in the phrase, attributed, perhaps apocryphally, to W.M. Turner, that "the sun is God”. An overview of how the sun figures in representational art is beyond the scope of our argument here. However, our concern is less with how the sun becomes aesthetic through its representation; rather, we are concerned with the sun’s generation of a conditional field within which a sense of the aesthetic emerges, one that becomes implicated in myriad practices at a range of sites.

From halos to beams, grids and dials, mystical personifications, circles, predictions and oracles, the story of aesthetic practice in relation to the solar is also that of the 'heliosphere' - a story of always already being inside and being exposed to the force of the solar. This is a force whose aesthetics is always excessive of representation and capture. Indeed, as Derrida reminds us, the aesthetic is, like the 
force of the solar, something excessive of measure or accountability, something that gives itself without counting, that gives with the "generous overabundance of a solar source” $(1981,12)$. However, it is fair to say that the technical articulation of relations with the sun has tended however to diminish its symbolic energy. As Luis FernándezGaliano argues, with respect to the invention of solar-walls and solar collectors for greenhouses the "sun has been bottled up, improving its thermal efficiency at the expense of its symbolic significance” (2000, 225).

Our concern here is not so much to revive a focus on the symbolic significance of the sun, but to think about how becoming attuned to solar energy in new ways might become part of the work of an elemental aesthetics. This poses particular challenges, some of which are conceptual, involving the elaboration of vocabularies sensitive enough to grasp the materialist energetics of processes that are palpable if not tangible, while also refusing to reduce accounts of these processes to a brute physical materialism. Another challenge is empirical and methodological, and is about making the force of the solar explicit in a manner that facilitates practices of sensing across spacetimes composed of diverse participants and devices (Gabrys 2014). Taken together, the challenge here is about crafting possibilities for making palpable the exposure and envelopment of bodies to the elementality of the sun through forms of conceptual, technical, and empirical experiment. This requires a commitment to a certain mode of inventiveness with respect to both technical devices and conceptual formations as part of aesthetic experiments, especially those to which we now turn.

A number of contemporary artistic works provide some important sources of orientation here. For instance, Rafael Lozano-Hemmer’s Solar Equation (2010), first shown in Melbourne's Federation Square, consists of an animated three-dimensional 
maquette of the sun projected onto a large tethered balloon. It was designed such that when ambient light fell below a certain level, the animation of the sun became visible on the surface of the balloon, accompanied by sounds of "rumbles, crackles, and bursts” produced by a “software simulation of solar activity” (Lozano-Hemmer 2010). ${ }^{2}$ Situated in relation to the symbolic significance of the sun and the mythologies that gather around it, Solar Equation deliberately foregrounded the aesthetic allure of the sun as an entity that draws attention to itself through levity, illumination, and colour, while also remaining withdrawn from us (Thrift 2010; Harman 2010). The elemental allure of the solar is also central to the aesthetics of Olafur Eliasson's The Weather Project (2003), about which geographers have written (see Massey 2003; Thornes 2008; Jellis 2015). The installation filled the Tate Modern's Turbine Hall with low-hanging fog, mirrored reflections, and yellow light from a field of monofrequency bulbs mounted behind a large orb on one wall. Visitors negotiated the artwork by investigating the apparatus behind the large sun (the circuits of which were readily apparent), watching their reflections in the ceiling mirrors, or witnessing the play of vapor in the vaulted space.

Although we might cite and discuss a range of other artworks and practices, we are particularly interested in artistic experiments that allow diverse constituencies to participate in the open-source crafting of devices for thinking, sensing, and moving with the force of the solar via an elemental aesthetics. With this in mind, in the remainder of the paper we wish to focus on the work of Argentinian born and Berlinbased artist Tomás Saraceno. Our claim is that Saraceno’s inherently collaborative and multisited work provides a particularly important set of provocations for cultivating an elemental aesthetics of the solar. This claim is based upon insights drawn from our involvement, participation, and research into events and works by 
Saraceno over the past three years (see Engelmann, McCormack and Szerszynski 2015; McCormack, 2015; Engelmann, 2016a; Saraceno, Engelmann and Szerszynnki 2015). For Engelmann, this involves ongoing ethnographic involvement in the creative life of Saraceno's art studio as part of the first $\mathrm{PhD}$ undertaken specifically in collaboration with the studio. For McCormack this involves a series of invited pieces of writing and speaking contributing to an ecology of ideas around these projects. We draw here upon insights generated through field research, participant observation, teaching, and many conversations with Saraceno himself in order to outline some of the key dimensions of his work with the solar. Crucially, we approach Saraceno’s work not as an illustration of an elemental aesthetics, but as exemplary of an ongoing experimental crafting that draws bodies and devices together in the generation of spaces within which the elemental comes to matter.

\section{The Lure of Becoming Solar}

It is important to note that not all of Saraceno's works address the question of the elemental force of the solar in a direct sense. Indeed Saraceno is well known for his multispecies collaborations with spiders (see Engelmann 2016b; Latour 2012; Stephens and Squire 2012); a 2017 exhibition at Museo de Arte Moderno de Buenos Aires (MAMBA) reflects on cosmic dust. Saraceno’s practice is a studio-based practice in which models, try-outs and key geometrical forms are tested and refined in a cavernous space in East Berlin accommodating (at the time of writing) around fifty studio assistants. However, the question of how to craft aesthetic works and experiences in relation to a solar elementality is a concern that can be traced through a number of his most important projects. In Poetic Cosmos of the Breath (2007-) for instance, an iridescent membrane of foil is inflated and warmed by the heat of the sun, 
forming a translucent enveloping shelter. This artwork's attention to envelopment echoes in what Saraceno and others call becoming aerosolar: exploring how the force of the solar might be harnessed to imagine, experiment, and devise ways of living in the air. This investment in collective life in the air is exemplified in Saraceno's longstanding ambition to construct and inhabit a Cloud City (2005-). There is a utopian dimension to these and other projects, one that echoes earlier experiments in untethered aerial design, including, for instance, the synergetics of Buckminster Fuller, the work of Frei Otto with the Institute of Lightweight Structures, and the pneumatic habitats of Ant Farm. One crucial difference in Saraceno's projects, and the theme to which we now turn, is the degree to which his work mobilizes and depends upon diverse communities of making, experiment and performance, exemplified in a project called Aerocene.

Aerocene is an 'open artistic project' and collective experiment in sensing and moving in the air with explicit orientations in citizen science, education and politics. In its naming, Aerocene refers to a post-Anthropocenic epoch in Earth's history: one in which the present "thermodynamic imaginary" (Moe, 2014) of extraction and combustion that has marked the industrial period is abandoned in favor of a renewed common investment in atmosphere as a lively and finite space. The name Aerocene also refers to a series of artworks that are reminiscent of balloons in their capacities to fly using air, wind and sun (but, as Saraceno often asserts, are not mere balloons).

For these authors, Aerocene marks a significant shift in Saraceno’s work and an important proposition for drawing out a collective attention to the elemental conditions through which new forms of political association might emerge. If Cloud Cities carries certain dimensions of techno-utopianism, Aerocene is what Pignarre and Stengers (2011) might term “an interstice” that activates novel forms of political 
enunciation. One of the core propositions of Aerocene experiments is that becoming airborne should be a process relying only on the energy of the sun and the air it moves. For Saraceno, zero carbon-based fuel should be used: an Aerocene sculpture must have the capacity to harness the energy of the sun in ways that make flight selfsustaining (see Figure 1). Unlike hot air or pressurized balloons, which require fuel or gas of different kinds to generate lift, Aerocene sculptures ascend by capturing solar radiation in a membrane capable of absorbing UV rays and re-radiating their energy into a body of air inside.

[Figure 1]

Figure 1: Tomás Saraceno

\section{Schellin and Aerocene Explorer trio}

The trio of Aerocene Explorer sculptures (left) and Schellin (in distance) were launched at dawn on March 4th 2017 from Schoenefelde, Germany. Schellin travelled 8 hours to North East Poland. Courtesy the artist, Wilhelm-Hack Museum, Ludwigshafen, and Museum Haus Konstruktiv, Zurich. (C) Photography by Tomás Saraceno, 2017

In its first two years, the Aerocene project was performed in the launch of a number of different sculptures, and the intensification of collaboration with several scientific and activist organizations. One sculpture, the D-OAEC Aerocene, was launched in White Sands, New Mexico in November 2015, and carried human participants. A pair of semi-reflective Aerocene sculptures floated inside the Grand Palais on the occasion of the COP21 climate conference in Paris. The Aerocene Explorer, a black tetrahedral sculpture that fits into a backpack complete with 
atmospheric sensors, tracking devices and cameras, has been developed by Studio Saraceno in collaboration with Sven Steudte, Alexander Bouchner and Nick Shapiro of the nonprofit citizen science group Public Lab as a tool for measuring atmospheric properties in community based political activism (see Figure 1). This point is crucial: Aerocene is a deliberate attempt to mobilize a community of makers, scholars and researchers from various institutional settings to create more accessible tools for becoming aware of the elemental conditions in which life in the air takes shape. ${ }^{3}$

In experimenting with solar-powered aerostats, Saraceno and the Aerocene are engaged in a fascinating history spanning university research, space agencies and amateur inventors. In this lineage for example we can place balloonist Tracy Barnes' and his all-black, tetrahedral Solar FireFly (1973), engineer Frederick Eshoo and the half-transparent Sunstat (1978) and Dominic Michaelis” “double envelope” solar balloon, successfully piloted across the English Channel by the celebrated balloonist Julian Nott in 1981. Solar balloons have been used extensively as vehicles for scientific experiment. The Centre National d'Études Spatiales (CNES), or the French space agency (with which Saraceno is currently collaborating) have designed and launched more solar balloons than any other organization. From the 1970s until 2008, CNES employed Montgolfier Infra-Rouge (MIR) balloons for research in atmospheric chemistry, stratigraphy, and the fluid dynamics of the upper troposphere and lower stratosphere. Unlike Saraceno’s Aerocene sculptures, these solar-powered balloons used helium for initial takeoff. Still, they could stay aloft for as long as 71 days (a record made by CNES in 2001), circling the globe on stratospheric winds, rising and falling in rhythm with the influx of energy from the sun.

Studio Saraceno’s relationship with other institutions and individuals in the field of solar-aerostatic flight troubles the definition of the artist's studio as an 
enterprise oriented toward marketing objects in the art world. Indeed, the results of Saraceno’s collaborative residency at the Massachusetts Institute of Technology (MIT) where he is working with Lodovica Illari, Glenn Flierl and Bill McKenna within the Earth, Atmospheric and Planetary Sciences (EAPS) department to visualize Aerocene sculpture journeys around the world, have been presented in conferences, tested in hackathons and showcased at the World Economic Forum in Davos. At the same time, such achievements beyond the traditional space of art pose obvious challenges to the way Saraceno's projects are funded, made public, and released into the world. Although beyond the scope of this article, it is important to acknowledge the risk-taking and vulnerability implied in Saraceno's attempt to make an art project 'open source' while sustaining a studio-based practice and the livelihoods of those who depend on it.

[Figure 2]

Figure 2: Tomás Saraceno

D-OAEC Aerocene launches at White Sands (NM, United States), 2015

The launches in White Sands and the symposium "Space without Rockets,” initiated by Tomás Saraceno, were organized together with the curators Rob La Frenais and Kerry Doyle for the exhibition “Territory of the Imagination” at the Rubin Center for the Visual Arts. The sculpture D-OAEC Aerocene is made possible due to the generous support of Christian Just Linde. The artistic experiment achieved two world records of the first and the longest solely solar manned flight. Courtesy the artist; Pinksummer contemporary art, Genoa; Tanya Bonakdar, New York; Andersen's Contemporary, Copenhagen; Esther Schipper, Berlin.

(C) Photography by Studio Tomás Saraceno, 2015 
The complexity of Aerocene collaborations are encapsulated in the launch of the D-OAEC Aerocene - an artwork that also qualifies as the world's 'first fully certified, manned solar balloon' - in White Sands, New Mexico (see Figure 2). The launch and the symposium "Space without Rockets” were organized by Saraceno together with the curators Rob La Frenais and Kerry Doyle for the exhibition “Territory of the Imagination” at the Rubin Center for the Visual Arts in El Paso, Texas. As a site, White Sands carries the significance of being the place where the first nuclear weapon tests were carried out - events that some scholars have argued herald the beginning of the Anthropocene (Waters et al., 2015). The solar-elemental performance of the D-OAEC Aerocene therefore makes an explicit commentary on the ecologies of toxicity that have characterized the last century (see also Engelmann, 2016a). The launch of the D-OAEC Aerocene was notably attended by John Powell, founder of JP Aerospace, a company that promotes affordable access to outer space via high-altitude platforms supporting experiments designed by school children across the USA (see Powell, 2008). Daniel Schulz and Danja Burchard of Studio Saraceno aided in the performance of the D-OAEC Aerocene launch. Enfolded in this event, therefore, were histories of solar-aerostatic flight and engineering, para-chemical histories of toxicity and geopolitics, and critical artistic interventions in the legacies of practice between humans and Earth’s elemental shell.

In some ways, perhaps, it might seem that this image (Figure 2) rehearses the experience of elevated transcendence through which the histories and geographies of much of aerodynamic and aerostatic flight is framed (see Dorrian and Poussin 2013). This, however, would be to caricature Saraceno's work, which as we have argued is 
less about rising above the earth than it is about devising new ways of being and becoming immersed in the elemental conditions of the milieu that we call the air. As is evident in the multi-faceted meanings of Aerocene, Saraceno's aerosolar endeavors don’t resolve into a clearly defined object for thought, or into a project to be interpreted through any single critical lens. Like his other works, they are better approached in terms of how they provide a cluster of propositions as lures for thinking and feeling (Whitehead 1978). Others have taken and developed these propositions in different ways by using Saraceno’s work to think about the networked spatiotemporality of the global (see Latour 2011a 2011b) and to consider ways in which the politics of the atmospheric might be re-imagined (PhilippopoulosMihalopoulos 2015).

Our interest here is in how Saraceno’s experiments offer possibilities for crafting an elemental aesthetics in relation to solar energy. In this respect Saraceno offers a number of important propositions. The first proposition is that an elemental aesthetics is less about representing the sun as an entity, and is more about thinking of the solar as an elemental condition in this midst of which forms of aesthetic atmospheric experience emerge. In Saraceno's work the sun is not represented or depicted as such: the aim instead is to make palpable the participation of solar energy in the generation of an elemental milieu in which different forms of living, moving, sensing, and feeling are possible. More so, perhaps, than works by Eliasson and Loranzo-Hemmer mentioned earlier, Saraceno’s solar works require us to become attuned to our immersion in the elemental conditions generated by the sun.

Second, Saraceno’s Aerocene project offers us an exemplar of a distinctive elemental aesthetics of sensing in which the locus of attunement is not necessarily the human body, but is distributed across various bodies and devices, human and non- 
human. Saraceno pursues this proposition through experiments in which the elemental force of the solar is sensed in a non-human device (the sculpture) responsive to the elemental circumstances in which it moves. This device responds to very fine changes in temperature and pressure, rising and falling in relation to the conditions in which it is immersed. Its capacity to sense emerges through the disagreement between the fabricated thing and its elemental conditions: a disagreement constituted through the micro-dynamics of pressure, given form in the shape of an inflated envelope that remains supple, flexible, and open to its outside. The sculpture is a "dissipative structure” which engages in controlled exchange of material and energy with its environment (Prigogine 1978). At the same time, the capacity of the Aerocene sculpture to sense the conditions of the elemental field in which it is immersed is translated into the bodies of those who work with it. For those who are carried aloft by this entity, it translates heat and light into the feeling of being aloft. And for those on the ground, it becomes a machine for amplifying the force of the solar in the act of witnessing something becoming airborne. The process of sensing the solar becomes a distributed one: it takes place across bodies and devices and the lines, tethers, and relations that hold them together.

A third proposition is that an elemental aesthetics involves a practice of collective assembly and fabrication. It requires scientific meteorology and engineering combined with an artful crafting, inventing and assembling of devices for sensing and moving with the solar. We take some orientation here from thinkers such as Tim Ingold and Michel Serres, each of whom, albeit in quite different ways, foregrounds the elemental as a central problematic and condition for thought, while also affirming the value of practical experiments that make its force sense-able and palpable. Consider, for instance, Ingold's accounts of experiments with kite-making 
(Ingold 2010b) that foreground the skilled process of becoming attuned to the relation between a device and the conditions that allow it to take to the air in ways that transform its capacities to affect and be affected. Serres' commitment to experiment is perhaps more implicit in his writing, but is nevertheless just as important. It can be gleaned, for instance, in his affirmation of sailing as a way of becoming attuned to the elemental as a circumstantial force that gathers around bodies (Serres 2012). In different ways, then, both Ingold and Serres emphasize that thinking with the solar involves ethico-aesthetic experiments with elemental forces through practices and devices that allow us to sense, feel and move with these forces.

The launch of an Aerocene sculpture is less about witnessing an entity take flight as it is about coordinated caring for a very unsteady, fragile thing. Despite its apparent simplicity, knowing how to work with this thing requires a distributed expertise across a group of willing collaborators. Even more so than pressurized or hot-air balloons, an Aerocene sculpture is a temperamental object. Ideally it should be launched at the crack of dawn, when the sun's rays are barely peering over the horizon, warming the air and the Earth. It must be inflated by holding its mouth open to the wind. Any concentration of stress on the material of the membrane can tear it. But perhaps the greatest disillusion in such an experiment arrives when clouds cover the sun, or when the wind becomes too strong. And there are still other risks. During an Aerocene launch in the course of a seminar co-taught by Engelmann together with Bronislaw Szerszynski, Melanie Sehgal, Janot Mendler de Suarez and Zoe Lüthi at the Anthropocene Campus in 2016, two Aerocene Explorer sculptures were inflated in perfect solar and elemental conditions on Berlin's Tempelhofer Feld, only to be halted by the local park service. The ironies of employing the old airport runway as a 
solar-aerostatic launch site notwithstanding, the physical weather had been perfect, but the institutional weather was not.

On the other hand, we can apprehend the conditions of a successful event by considering the launch of the Aerocene Gemini (see Figure 3). The launch took place on August 27 $7^{\text {th }}, 2016$ near Berlin. The two Aerocene sculptures that would be tethered together in flight required several people to attend to their inflation, to hold the membranes gently in place, to attach the necessary GPS devices, cameras and instruments. Gathered around it were studio assistants, two radio-amateurs, Nick Shapiro of Public Lab, Tomás Saraceno and many other 'friends of the Aerocene'. As the sculpture readied for launch, it was touched, steadied and adjusted by many hands: the participants were communicating to each other and to the sculpture through the tension and force rippling through the membrane. There was almost no wind. At around 7:30am the sculptures floated up a dozen meters high, payloads trailing on ropes below. For some time, nothing happened. The two-part body hung there, like a pair of fragile creatures waiting for change, absorbing the sun's eager rays.

The ascent that followed was gentle. Aerocene Gemini approached a line of tall trees in the distance, and as the earthbound humans held their breaths, the sculptures barely cleared the treetops, payloads intact (Šlapšinskaitè, personal communication, 2016). Then they disappeared into blue sky, dissolving into two particles whose presence had been so palpably felt an hour earlier as two membranous bodies hanging motionless over the field; two aerosols attracting the assembly of practitioners, technologies, predictions and hopes in those particular cosmic conditions. In this moment, the experience of bringing the sculpture to life became both ethical and aesthetic. It became ethical in the sense that to participate in the launching of this fragile entity was to contribute to the tending of something fragile 
taking shape. And it became aesthetic because the experience extended the elemental and atmospheric space of expression in which participation took place. As the earthbound participants, including this paper's authors, followed the Aerocene Gemini's path via APRS radio transmissions as it flew across Germany and Poland for the remainder of the day, the sculpture's journey became the aesthetic shape of relational immersion in an elemental field - one whose affects are felt on the earth but whose provenance is solar.

[Figure 3]

Figure 3: Tomás Saraceno.

Saturday, August 27, 2016: Aerocene Gemini travels 605 km distance, floats over 12 hours, reaches 16.283 m altitude. All without any carbon, fossil fuels, helium, hydrogen, burners, or engines - using only air currents and the heat of the sun. Courtesy the artist; Pinksummer contemporary art, Genoa; Tanya Bonakdar Gallery, New York; Andersen's Contemporary, Copenhagen, Esther Schipper, Berlin. (C) Photography by Tomás Saraceno, 2016

A fourth proposition for an elemental aesthetics emerging from Saraceno’s work concerns the speculative nature of the geographies that it generates. These are experiments that are not necessarily based upon the primacy of identifying a clear direction of travel: in that sense, they promise a way of moving that is irreducible to the logistical imperative of other forms of aerial transport. Aerocene sculptures have the capacity to journey according to the prevailing weather conditions in ways that can be tracked without necessarily being determined. But in a less literal sense, Aerocene sculptures are devices for speculative journeys in a geographical, 
philosophical ethico-aesthetic, and political sense. These journeys are speculative because they are about experimenting with different ways of configuring materials, bodies, and elements. They are also speculative because they seek to open up new trajectories for thinking the elemental through a form of carefully prepared collective choreography. Choreography is always a matter of partial dirigibility: it is about putting bodies in movement while recognizing that this movement is an ongoing response to the relational circumstances in which it takes place. Similarly, Aerocene artworks are choreographic experiments revolving around the question of how to move with the elemental when the conditions themselves are in motion. Elemental conditions therefore become collaborators in the undertaking of journeys whose destination is always open to variation. In this context, the question is how to choreograph relations with and between multiple bodies in the air, with the wind and with thermal convection, using knowledge of atmospheric dynamics, of force, of wind strength, of tension, of energy, etc. This is a choreographic gesture towards an alternative future that takes shape through experiments with what Jill Bennett (2012) calls the "practical aesthetics" of air and atmosphere.

\section{The political aesthetics of the solar}

All of this is both interesting and important as far as the promise of elemental aesthetics is concerned. However, we also wish to reflect upon how the elemental aesthetics emerging through the kinds of experiments undertaken by Saraceno and his collaborators might produce occasions for generating different spaces of the political. Central to this is the fact that Saraceno's work is organized around the promise of crafting aesthetic devices that allow the elementality of the solar to be made explicit, made more palpable, and experimented with in a way that is open and accessible. For Saraceno there is value in doing this because it allows the elemental conditions in 
which life is immersed to be disclosed, at least partially. But these works can also contribute to the crafting of distinctive kinds of political spaces in which diverse participants gather.

To illustrate this we turn briefly to another work, Museo Aero Solar, initiated by Saraceno and Italian writer Alberto Pesavento together with a number of volunteers and collaborators in 2007. Museo Aero Solar is an aerostatic sculpture fabricated from reused plastic bags simply cut and patched together with tape, or sealed with heat (see Figure 4). The project has been performed in the United Arab Emirates, Columbia, Italy, the US and Germany, among many other places. Central to the promise of Museo Aero Solar is the possibility of putting a practical elemental aesthetics into wider circulation through an ongoing process of collective assembly and fabrication. It takes the work and experience of fabrication - of designing, assembling and taping - outside the confines of relatively privileged sites, inviting diverse participants to contribute.

\section{[Figure 4]}

Figure 4: Museo Aero Solar

A collective work co-founded by Tomás Saraceno, Alberto Pesavento and many other friends, 2007. Photography by Janis Elko from Museo Aero Solar, Prato, Italy Source: $\underline{\text { www.museoaerosolar.wordpress.com }}$

The fact that this process takes place through such mundane practices or materials does not make it any less important. The work of giving shape to the envelope becomes a way of participating in the shaping of a relation-specific thing in order to put it in motion, allowing it to catch the sun and the wind such that it might 
generate circumstantial gatherings. In the performance of Museo Aero Solar, shape and volume are not only extensive products of matter and air, but also of collective action and assembly. This is a process of giving shape to volumes that stand apart from us in such a way that they become reminders of our participation in their generation.

Just as importantly, Museo Aero Solar uses everyday materials in a way that transforms the political and aesthetic economy in which these materials circulate. The shape of the balloon emerges from the promise of the very material - plastic - and the very envelope - the plastic bag - that serve as the signature fabric and form of the Anthropocene. If we think of the materials from which alluring lighter-than-air technical devices might be fabricated, we rarely think of cheap, gaudy shopping bags. To use plastic in order to fabricate a device for becoming airborne is to take material associated with waste and render it anew. Or put another way, this process resingularizes the value of this material, transforming it from one that exemplifies the disposability of capital, to one that expresses an ecology of the elemental (Guattari, 1995).

Because of this, Saraceno's aerosolar works do more than act as a lure for thought. They become attractors that allow participants to contribute to the fabrication of this lure with materials that confront them with the very conditions in which thought takes place. Museo Aero Solar was performed in the exhibition Pour un monument à l'Anthropocène curated by Bruno Latour and Bronislaw Szerszynski at Les Abattoirs in Toulouse (2014); at the COP20 Climate Conference in Lima, Peru; at 21er Haus, Vienna in the exhibition Tomás Saraceno: Becoming Aerosolar (2015); and at the Palais de Tokyo on the occasion of the COP21 climate conference in Paris (2015). At each of these sites, the process of donating reused plastic bags, cutting 
them, and taping them together drew people to a space of shared activity and speculation organized around the question of whether or not something made of plastic bags might fly. Participants kneeled and smoothed the corners and edges of the sculptures' plastic components, for days and nights on end. They decided how to fold the surface on itself to make an enclosure, and debated where to cut, shape and tie it. It is also remarkable how often people react joyfully upon entering the inflated sculpture. Just as the process of making involves the slow invention of a structure of interstices, being in this sculpture generates a distinctive structure of feeling - of gasps, smiles, shouts and laughs. These sculptures take shape as envelopes of affective experience that allow participants to be exposed to the elemental conditions of this experience.

When Intiñan, a variation of Museo Aero Solar, was inflated at the Development and Climate Days Conference during COP20 in Lima, the entire conference paused while delegates streamed into a courtyard to witness the event. As the first seven people - including IPCC chairman Chris Field - entered the growing membrane, a voice exclaimed: This is the best thing that has ever happened to politics! ${ }^{4}$ This line is hyperbolic, but it also conveys the intensity of moments with which a politics of the solar can be invented or refigured. Such moments show how an elemental aesthetics might also be critical-political, albeit not in a conventional or familiar sense, rather, in the sense that they facilitate a mode of gathering or assembly. If we follow Bruno Latour (2004), these works can enact the claim that the function of critique might be as much to generate spacetimes in which participants gather, as it is about dismissing the conditions of the contemporary. In the shape of Museo Aero Solar, the process of collective fabrication and assembly produces an envelope for generating and sensing differences. The process of learning to cultivate 
attentiveness to the thresholds of these differences can be understood, we would argue, as part of a micro-politics: a micro-politics in which new senses of the political emerge through variations in the elemental conditions in which bodies - human and non-human - are enveloped. These variations are not necessarily repeatable, of course: they are circumstance-, or occasion-specific. We might understand this as a refrain for a micro-political aesthetics of the elemental. Refrains are patternings of materiality that express the tendency to return while never doing so in quite the same way (See Deleuze and Guattari, 1987). They tend towards stability while never really becoming formalized as objects. Refrains can, of course, close in on themselves, becoming patterns of deathly repetition. However, they can also remain open to the excessive fringe of novelty, to the halo of turbulent variability at their edges. The collaborative projects of the Aerocene or of Museo Aero Solar are refrains: alluring calls that act as generative territories of possibility through which repetition produces differences that can be sensed.

These calls seed an ecology of practices that proliferates around the prospect of becoming elemental through the inventive patterning of practices, devices and materials. Enunciating these calls, as Stengers (2005) tells us, is critical to any inventive ecology of practices. The promise of the Aerocene is one such call: it holds open the lure of an ecology of practices for remaking capacities to sense the conditions of the elemental on which diverse forms of life depend. This lure does not necessarily take the form of a monumental object or entity but is distributed through a range of more modest devices or instructions. As part of this, Saraceno is engaged in ongoing efforts to distribute the technical capacity to become attuned to the elemental. For instance, in the Aerocene Newspaper (2015) produced on the occasion of the COP21 Climate Conference and included in every Aerocene Explorer kit, Saraceno 
included a user's guide to building and launching an Aerocene sculpture. The practical work of elemental aesthetics in such a context involves producing a series of manuals for crafting and modifying atmospheric sensors that may be attached to sculptures, and used to perform experiments as they fly. In resonance with a body of work on citizen sensing (Gabrys 2014) such work reminds us of the importance of crafting aesthetically alluring platforms through which to cultivate technical experiments with elemental sensing.

\section{Conclusion}

Drawing upon the work of Tomás Saraceno, in this paper we have been arguing that artistic experiments with the force of the solar can help us cultivate an elemental aesthetics. Through his work with what appear as deceptively simple devices, Saraceno's experiments with solar energy show us how it possible to attune to the sensual propositions made by elemental matter-energy. Saraceno’s collaborative work shows us how the solar is more than a term that denotes energy transmitted from the sun and received or absorbed by the earth. It is, rather, a crucial force shaping the elemental field in which forms of feeling and sensing take shape. Equally, his work demonstrates how an elemental aesthetics of the solar go beyond the question of how to represent the sun artistically. Rather, this aesthetics involves the ongoing process of learning to become affected by the force of the elemental through experiments with a range of crafts, materials, and devices as they are moved, pulled and pushed by the elemental force of the sun.

Organized around the speculative promise of the Aerocene, these experiments in elemental aesthetics are important because they temper the hubris implicated in claims about the Anthropocene, reminding us that earthly ecologies and forms of life continue to be shaped by forces beyond the Earth and irreducible to human impact. To 
focus attention on such forces reminds us just how parochial are debates about the Anthropocene and Capitalocene (among other names), putting in perspective claims about the world-shaping influence of human agency, and forcing us to map terrestrial concerns, however urgent, through the unsettling spatio-temporality of what philosopher Timothy Morton (2013) has called 'hyper-objects': entities too massive in spatial and temporal scale for us to grasp within traditional epistemological and ontological frames of reference. These questions also remind us that the horizon of thought, ethics, politics, and life itself is not only terrestrial but extends to the solar, and is framed by what Jean François Lyotard (1993) names the "solar catastrophe": the certainty of the death of the sun and everything upon which it depends. Because of this, to paraphrase Ray Brassier, more than anything else, the question in the shadow of which all thinking takes place is the question of the "history of the earth we live on and of its relation to the sun” $(2003,421)$.

The experiments we have discussed here remind us that the deliberate foregrounding of the aesthetic is a critical dimension of any attempt to rethink the technical and political terms of our relations with the sun and with solar energy. These experiments force us to address the question of the solar in ways that go beyond a studied critique, supplementing this critique with an active participation in the collective elemental conditions in which life takes place. Projects such as Cloud Cities and the Aerocene appear utopian or elitist only if we restrict ourselves to thinking of such cities and sculptures as literal aerial versions of a terrestrial polis. Rather, central to these projects is the investigation of how countless different forms of life, from microorganisms to spiders, live aloft in ways we do not yet fully understand (see Aerocene Newspaper). The potential presence of these living things might force us to expand the horizons of elemental kinship: doing so, however, requires the elaboration 
of an aesthetics of the elemental through a range of performances and sensing practices that might renew our collective involvement in the air. In this way a politically attuned elemental aesthetics might involve the distribution of agency across different spaces and species that can sense, feel, and move with the force of the solar.

Saraceno’s Aerocene sculptures offer an especially alluring set of experiments for disclosing how the force of the solar can shape spacetimes of sensing, moving and thinking at the contemporary conjuncture (Engelmann, McCormack and Szerszynski 2015). His work propositions us to imagine a partial untethering of the solar from the extractive, terrestrial logics of the speculative economies of the Anthropocene. In doing so Saraceno’s work exemplifies the promise of Szerszynski and Galaragga’s (2012) “climate artist:” an artist who collaborates with rather than masters the elemental conditions upon which life depends. These collaborations facilitate excursions into air and atmosphere that sensitize bodies - human and nonhuman - to the solar and elemental conditions that make those collaborations possible. In the process, these aesthetics reach beyond the act of representing or symbolizing to foreground the immersive elemental conditions in which forms of life take place. Following Stengers (2005), we can think of the scope of the elemental aesthetics emerging from Saraceno’s work as an elaboration of a cosmological politics. As such, it has parallels with the 'cosmopolitical experiments' articulated by Latour (1999) and put to work by Hinchliffe et al. (2005) and Whatmore and Landström (2011) in ways that involve taking risks to unsettle the spheres of research, science, politics or art. Critically, part of the cosmopolitical significance of Saraceno's experiments is the degree to which they radically complicate the scale of the elemental and our capacities to sense its force. They remind us that the 
phenomenological experience of elemental variations is merely a circumstantial expression of forces that are excessive of the earthly and terrestrial. The point of this is not to diminish the capacities of the human in relation to the sublime prospect of the cosmos. It is rather to encourage “empowering experiments” (Pignarre and Stengers 2011) that do not reduce to purely human categories, but situate human practices as belonging to myriad others. Saraceno’s experiments, we would suggest, offer possibilities for empowering novel forms of association between humans and non-humans through which the conditions of the elemental can be made to matter. In some ways Saraceno's work shows us how an elemental aesthetics is characterized by what philosopher Don Cupitt calls an expressive openness to the elementality of the world (see also Cupitt, 1995). Such an openness also echoes Nietzsche’s (1968) articulation of ‘solar love’. We certainly would not endorse a naïve affirmation of this openness, nor do we think that Saraceno does. Indeed, if anything, his work shows us how the ethics of elemental aesthetics can be understood in terms of the relation between exposure and envelopment. But we do think that there is an importance resonance between the kind of aesthetics that emerges from such openness and Saraceno’s artistic experiments. There is something about Saraceno's efforts to craft fragile envelopes from materials stitched and seamed together that echoes Cupitt's claim that in order to respond to the elemental "we need sentences, text(ile)s, that weave together into a continuous flowing process, pouring out and passing away, biology and language, flesh and word, Natur and Geist, the vibrating energies of the physical world and our own pulsating feelings. We need ways of writing the unity and continuity of the world - its continual coming to pass, and also its continual passing away” (ibid. 55). Cupitt foregrounds writing as an aesthetic practice: however, as we have been trying to show in this paper, an elemental 
aesthetics needs to be elaborated through a wider and more diverse ecology of artistic experiments that mobilise a range of materials, bodies and devices. It can be pursued, for instance, through the crafting of different incarnations of air's poetics through a range of artistic practices and interventions (Choy 2011; Engelmann 2015b)

Attention to and participation in these artistic experiments, we argue, can inform the shape and ethos of geographical thinking about the elemental and aesthetic, not least by helping us realize that the elemental conditions of the aesthetic are always mixed. It also helps us grasp that thinking with elemental is about performing a particular form of speculative and experimental empiricism. It is speculative in as much as it is about inventing ideas and concepts through which to sense how the elemental conditions of thought and action, ethics and aesthetics, might be changing. And it is empirical because its mode of speculation takes place through experiments with processes and materials for harnessing and sensing the force of the solar as an elemental field. As a contribution to the wider elaboration of a geographical aesthetics, this kind of elemental aesthetics offers a series of conceptual, methodological, and ethico-political waypoints for generating something new under the sun. It helps us imagine an elemental aesthetics through an attunement to the force of the solar as it generates fascination, lures bodies, and cascades into the atmospheres and envelopes of life on our planet.

\section{References}

Adey, P. 2015. Air's affinities: geopolitics, chemical affect and the force of the elemental. Dialogues in Human Geography 5 (1): 54-75. 
Adey, P., 2014. Security atmospheres or the crystallisation of worlds. Environment and Planning D: Society and Space 32(5): 834-851.

Adey, P. 2010. Aerial life: mobilities, spaces, affects. London: Wiley-Blackwell.

Bachelard, G. 1988. Air and dreams: an essay on the imagination of movement. Trans. E Farrell and F. Farrell. Dallas: Dallas Institute Publications.

Bataille, G. 1991. The accursed share, vol. 1. New York: Zone Books.

Bennett, J. 2010. Vibrant matter: a political economy of things. Durham, NC: Duke University Press.

Bennett, J. 2012. Practical aesthetics: events, affects, and art after 9/11. London: I.B. Tauris.

Bogost, I. 2012. Alien phenomenology: or what it's like to be a thing. Minneapolis: University of Minnesota Press, Kindle Edition.

Brassier, R. 2003. Solar catastrophe: Lyotard, Freud, and the death-drive. Philosophy Today 47 (4): 421-430.

Buck, H.J. 2015. On the possibilities of a charming anthropocene. Annals of the Association of American Geographers. 105 (2): 369-377

Choy, T. 2011. Ecologies of comparison: an ethnography of endangerment in Hong Kong. Durham, NC: Duke University Press.

Clark, N., 2012. Sex, politics and inhuman artistry. Dialogues in Human Geography 2 (3): $271-275$.

Clark, N. 2013. Geoengineering and geologic politics. Environment and Planning A 45 (12): 2825-2832.

Clark, N. 2014. Geo- politics and the disaster of the Anthropocene. The Sociological Review 62 (S1): 19-37. 
Cohen, J. J. 2011. An abecedarium for the elements. postmedieval: a journal of medieval cultural studies 2: 291-303.

Cohen, J.J. 2014. Elemental Relations. O-Zone: A Journal of Object-Oriented Studies 1: 53-61.

Cohen, J. J. \& Duckert, L. eds. 2015. Elemental ecocriticism: Thinking with earth, air, water, fire. Minneapolis: University of Minnesota Press.

Crutzen, P. J. 2006. The “Anthropocene”. Springer Berlin Heidelberg, 13-18.

Cupitt, D. 1995. Solar ethics. London: SCM Press.

Deleuze, G. and Guattari, F. A thousand plateaus. Trans. Brian Massumi. London: Athlone, 1987.

Derrida, J. 1981. Economimesis. Diacritics 11 (2): 2-25

Dixon, D. 2009. Creating the semi-living: On politics, aesthetics and the more-thanhuman. Transactions of the Institute of British Geographers 34 (4): 411-25.

Dixon, D., H. Hawkins, and E. Straughan. 2012. Of human birds and living rocks: Remaking aesthetics for post-human worlds. Dialogues in Human Geography 2 (3): 249-70.

Dorrian, M. and Pousin, F. eds., 2013. Seeing from above: the aerial view in visual culture. IB Tauris.

Eliasson, O. and Kuo, M. 2015. Conversation at the dynamo symposium. Berlin: Akademie der Kunst, May 2015.

Engelmann, S. 2015a. More-than-human affinitive listening. Dialogues in Human Geography 5 (1): 76-79.

Engelmann, S. 2015b. Towards a poetics of air: sequencing and surfacing breath. Transactions of the Institute of British Geographers 40 (3): 430-444.

Engelmann, S. 2016a. Cosmic Circuitry. in A. Oosterman (Ed.), Volume 47. 
Engelmann, S. 2016b. Social spiders and hybrid webs at Studio Tomás Saraceno. cultural geographies DOI: 1474474016647371.

Engelmann, S., McCormack, D.P., and Szerszynski, B. 2015. Becoming aerosolar and the politics of elemental association. In Tomás Saraceno: Becoming Aerosolar. Vienna: 21er Haus, Vienna, 67-101.

Evans, F. 1998. “Solar love”: Nietzsche, Merleau-Ponty, and the fortunes of perception. Continental Philosophy Review 31 (2): 171-193.

Fernández-Galiano, L. 2000. Fire and memory: on architecture and energy. Trans. G. Cariño. Cambridge, MA: MIT Press.

Fisher, D. 2010 Much ado about (practically) nothing: a history of the noble gases. Oxford: Oxford University Press.

Gabrys, J. 2014. Programming environments: environmentality and citizen sensing in the smart city. Environment and Planning D: Society and Space 32 (1): 30-48.

Galaragga, M. and Szerszynski, B. 2012. Making climates: solar radiation management and the ethics of fabrication. In Engineering the climate: the ethics of solar radiation management, ed. C. Preston and A. Borgmann. Lanham M D: Lexington Books, 221-235.

Guattari, F. 1995. Chaosmosis: an ethico-aesthetic paradigm. Trans. P. Bains and J. Pefanis. Sydney: Power.

Harman, G. 2010. Guerrilla metaphysics: phenomenology and the carpentry of things. Peru, Illinois: Open Court Publishing.

Haraway, D.J., 2016. Staying with the trouble: Making kin in the Chthulucene. Duke University Press.

Hawkins, H. 2013. Geography and art. An expanding field: site, the body and practice. Progress in Human Geography 37(1): 52-71. 
Hawkins, H. Marston, S., Ingram, M., and Straughan, E. 2015. The art of socioecological transformation. Annals of the Association of American Geographers 105 (2): 331-341.

Hawkins, H. and Straughan, E. eds. 2015. Geographical aesthetics: imagining space, staging encounters. Farnham: Ashgate Publishing.

Hinchliffe, S., Kearnes, M. B., Degen, M., \& Whatmore, S. 2005. Urban wild things: a cosmopolitical experiment. Environment and planning D: Society and Space 23(5): 643-658.

Ingold, T. 2010a. Footprints through the weather-world: walking, breathing, knowing. Journal of the Royal Anthropological Institute 16, Issue supplement 1: 121-139.

Ingold, T. 2010b. Bringing things back to life: Creative entanglements in a world of materials. ESRC National Centre for Research Methods: Working Paper Series 15. http://eprints.ncrm.ac.uk/1306/, accessed January 2016.

Ingold, T. 2011. Being alive: essays on movement, knowledge and description. London: Taylor \& Francis.

Ingram, A. 2016. Rethinking art and geopolitics through aesthetics: artist responses to the Iraq war. Transactions of the Institute of British Geographers 41 (1): 1-13.

Jackson, M., Fannin, M. 2011. Letting geography fall where it may: aerographies address the elemental. Environment and Planning D: Society and Space 29 (3): $435-444$.

Jellis, T. 2015. Spatial experiments: art, geography, pedagogy. Cultural Geographies, 22 (2): 369.

Kingsbury, P. 2016. Rethinking the aesthetic geographies of multicultural festivals: a Nietzschean perspective. Annals of the Association of American Geographers 106 (1): 222-241. 
Latour, B. 2011a. Some experiments in art and politics. E-Flux Journal, March 2011, http://www.e-flux.com/journal/some-experiments-in-art-and-politics/.

Latour, B. 2011b. Network theory, networks, societies, spheres: reflections of an actor-network theorist. International Journal of Communication 5: 796-810.

Latour, B. 2004. The politics of nature: how to bring the sciences into democracy. Paris: Édition la Découverte.

Latour, B. 1999. Pandora's Hope: Essays on the Reality of Science Studies. Cambridge, MA: Harvard University Press.

Levi, P. 2000. The periodic table. London: Penguin.

Lorimer, J. 2012. Aesthetics for post-human worlds: difference, expertise and ethics. Dialogues in Human Geography 2(3): 284-287.

Lorimer, J. 2015. Wildlife in the Anthropocene. University of Minnesota Press.

Lyotard, J.F. (1993) The inhuman: reflections on time. Trans G. Bennington and R. Bowlby. Cambridge: Polity Press.

Macnaghten, P. and Szerszynski, B., 2013. Living the global social experiment: an analysis of public discourse on solar radiation management and its implications for governance. Global Environmental Change 23 (2): 465-474.

Manning, E. 2010. Relationscapes: movement, art, philosophy. Cambridge, MA: MIT Press.

Martin, C. 2011. Fog-bound: aerial space and the elemental entanglements of bodywith-world. Environment and Planning D: Society and Space 29: 454 - 468.

Massey, D. 2003. Some times of space. In Olafur Eliasson: The weather project, ed. Susan May, Exhibition Catalogue. London: Tate Publishing, 107-118.

McCormack, D. P. 2009. Aerostatic spacing: on things becoming lighter than air. Transactions of the Institute of British Geographers 34 (1): 25-41. 
McCormack, D. P. 2014. Atmospheric things and circumstantial excursions. Cultural Geographies 21 (4): 605-625

McCormack, D. P. 2015. Envelopment, exposure, and the allure of becoming elemental. Dialogues in Human Geography 5 (1): 85-89.

McCormack, D.P., 2016. Elemental infrastructures for atmospheric media: On stratospheric variations, value and the commons. Environment and Planning D: Society and Space, p.0263775816677292.

Mentz, S. 2010. Strange Weather in King Lear. Shakespeare 6(2): 139-152.

Moe, K. 2014. Insulating modernism: isolated and non-isolated thermodynamics in architecture. Birkhäuser.

Morton, T. 2013. Hyperobjects: philosophy and ecology after the end of the world. Minneapolis: University of Minnesota Press.

Nietzsche, F. 1968. Thus spoke Zarathustra. In The Portable Nietzsche, ed. and trans. W. Kaufmann. New York: The Viking Press, Inc.

Padilla, J.R. 2009. Seamus Heaney’s Elemental Ecopoetics: Earth, Water, Air and Fire. Journal of Ecocriticism, 1(2): 21-30.

Philippopoulos-Mihalopoulos, A. 2015. Spatial justice: body, lawscape, atmosphere. London: Routledge.

Prigogine, I. 1978. Time, structure, and fluctuations. Science, 201(4358), 777-785.

Ranciere, J. 2004. The politics of aesthetics: the distribution of the sensible. Trans. G. Rockhill. London: Continuum.

Saraceno, T. 2011. Cloud Cities, eds. Marion Ackerman, Daniel Birnbaum, Udo Kittelmann, and Hans Ulrich Obrist. Berlin: Distanz Verlag. 
Saraceno, T., Engelmann, S., and Szerszynski, B. 2015. Becoming Aerosolar: from solar sculptures to cloud cities. In Art in the Anthropocene, eds. E Turpin and H. Davis. London: Open Humanities Press.

Stephens, A. C., and Squire, V. 2012. Politics through a web: citizenship and community unbound. Environment and planning D: society and space 30 (3): 551567.

Szerszynski, B. 2013. Geoengineering and the shape of the Earth. Paper presented at the workshop Geoengineering on the Climate Change Agenda, Paris, 11 October 2013.

Serres, M. 2012. Biogea. Trans. Randolph Burks. Minneapolis: Univocal.

Serres, M. 2008. The five senses: a philosophy of mingled bodies. Trans. M. Sankey and P. Cowley. London: Continuum.

Sharpe, S. 2013. The aesthetics of urban movement: habits, mobility, and resistance. Geographical Research 51 (2): 166-172.

Shaviro, S. 2014. The universe of things: on speculative realism. Minneapolis: University of Minnesota Press.

Squire, R., 2016. Rock, water, air and fire: Foregrounding the elements in the Gibraltar-Spain dispute. Environment and Planning D: Society and Space, 34(3), pp.545-563.

Stengers, I. 2005. Ecology of practices and technology of belonging. http://www.imbroglio.be/site/spip.php?article43.

Thornes, J. 2008. Cultural climatology and the representation of sky, atmosphere, weather and climate in selected art works of Constable, Monet and Eliasson. Geoforum 39 (2): 570-581. 
Thrift, N. 2010. Understanding the Material Practices of Glamour. In The Affect Theory Reader, eds. Melissa Gregg and Gregory Seigworth, 289-309. Durham, NC: Duke University Press.

Waters, C. N., Syvitski, J. P., Gałuszka, A., Hancock, G. J., Zalasiewicz, J., Cearreta, A., ... and Barnosky, A. 2015. Can nuclear weapons fallout mark the beginning of the Anthropocene Epoch? Bulletin of the Atomic Scientists 71(3): 46-57.

Whatmore, S. J., \& Landström, C. 2011. Flood apprentices: an exercise in making things public. Economy and Society 40(4): 582-610.

Whitehead, A.N. 1978. Process and Reality. New York: The Free Press.

Acknowledgments: The authors would like to thank the editors and three anonymous reviewers for their helpful comments. Particular thanks go to Tomás Saraceno and to Sofia Lemos, Ignas Petronis, Anna Garbus and the team at Studio Saraceno. The authors also acknowledge the insights of Bronislaw Szerszynski in further inspiring our thinking on the Aerocene and the elemental. Derek McCormack would like to acknowledge the support of a British Academy Mid-Career Fellowship.

\section{Author Biographies:}

Sasha Engelmann is Lecturer in GeoHumanities at Royal Holloway University of London. Her work explores creative experiments in sensing atmospheric space, and her doctoral research was undertaken in collaboration with Studio Tomás Saraceno. 
Derek P. McCormack is Associate Professor in the School of Geography and

Environment at the University of Oxford. He has written on nonrepresentational

theory, affect, and, more recently, atmospheres.

\footnotetext{
${ }^{1}$ This concept has been set into motion in various ways across the human and natural sciences, and here we work with a definition near to that coined by Paul Crutzen and Eugene Stoermer, and developed in the deliberation of the Anthropocene Working Group. The anthropocene denotes the present time interval, in which many geologically significant conditions and processes of the Earth System are altered by human activities.

${ }^{2}$ See http://www.lozano-hemmer.com/texts/downloadable/SolarEquation2LQNB.pdf. Last accessed 20 January 2016.

${ }^{3}$ The description of the Aerocene Community on the project's dedicated website reads: "Aerocene is an open project initiated by artist Tomás Saraceno and developed by Aerocene Foundation... The Aerocene project's primary collaborators and supporters are the Center for Art, Science \& Technology (CAST) at the Massachusetts Institute of Technology (MIT), CNES (French National Space Agency), CCK Argentina, Public Lab, The Goethe Institute, Radioamateur, Freifunk, and IAK architecture-related Art Institute at Technische Universität Braunschweig, TBA21, among others. (www.aerocene.org/contributors)

${ }^{4}$ From COP20 video footage, Studio Tomás Saraceno, 2014.
} 